\title{
Critical Steps: A Non-Interventional, Multicenter, Prospective, Observational Study on Critical Handling Errors with DPI Use, in Asthma and COPD Patients
}

\author{
Demosthenes Bouros ${ }^{1,2 *}$ and Mina N Evangeliou ${ }^{2,3}$ \\ ${ }^{1}$ First Academic Department of Pneumonology, University of Athens Medical School, Hospital for Diseases of the Chest "Sotiria", Athens, Greece \\ ${ }^{2}$ Critical Steps Study Group, Greece \\ ${ }^{3}$ Elpen Pharmaceutical Co. Inc., Pikermi Attica, Greece
}

\begin{abstract}
Objective: Correct inhalation technique is crucial for drug delivery to the airways of Asthma and COPD patients. The aim of the current study is to assess the usability of three commonly used DPI devices in Greece in Asthma and COPD patients.

Methods: This was a non-interventional, multicenter, observational study that enrolled 755 patients (409 Asthma and 346 COPD). Evaluation of device use was performed at baseline (day 0), immediately after correct use demonstration by the investigator, and final visit (day 30). Assessment was based on 8-step device-specific checklists where all the required inhalation maneuvers were described. Primary variable was the number of critical errors observed during baseline and final visit. The ACQ and CAT questionnaires were used to record patients' perspective about their condition, and the FSI-10 questionnaire to depict patients' feeling of satisfaction from inhaler use.

Results: More than $70 \%$ of the patients performed all inhalation maneuvers correctly right after the first demonstration by pneumonologist. At final visit approximately $85 \%$ of Diskus ${ }^{\circledR}, 93 \%$ of Elpenhaler ${ }^{\circledR}$, and $75 \%$ of Turbuhaler ${ }^{\circledR}$ users did not make critical errors that affect drug delivery to the lungs. Elpenhaler ${ }^{\circledR}$ had the lower error rates for critical steps at baseline and final visits $(7.0 \%$ and $2.5 \%$ respectively), whereas the corresponding rates for Diskus ${ }^{\circledR}$ were $7.3 \%$ and $4.9 \%$, and for Turbuhaler ${ }^{\circledR}, 8.5 \%$ and $7 \%$ respectively. All patients had improved ACQ and CAT scores and were at least fairly satisfied by their inhalers.

Conclusions: Demonstration of inhalation technique is of paramount importance, while prescribing an inhaled therapy. Improvement over one-month use was more evident in Elpenhaler ${ }^{\circledR}$ device. The lower error rates on critical steps for Elpenhaler ${ }^{\circledR}$ reported at baseline and final visits in combination with the observed improvements in ACQ, CAT and FSI-10 scores suggest better adherence to therapy and disease control.
\end{abstract}

Keywords: DPIs; Critical errors; Inhalers; Diskus ; Elpenhaler ${ }^{\circledR}$; Turbuhaler; ${ }^{\circledR}$ Asthma; COPD

\section{Introduction}

Asthma and chronic obstructive pulmonary disease (COPD) are two of the leading causes of morbidity, mortality and economic burden worldwide [1]. Epidemiological data of Asthma in Greece are limited. A national prevalence survey on Asthma conducted from the Asthma Working Group of the Hellenic Thoracic Society has shown that the prevalence of physician-diagnosed Asthma was 9\% and Asthma incidence was calculated as 16 new cases per thousand people [2]. As far as COPD is concerned, the estimated prevalence of COPD for Greece in total population has been reported to be $8.4 \%$ [3].

Chronic respiratory diseases represent $5 \%$ of total disease burden and $8.3 \%$ of chronic disease burden worldwide, accounting for more than 4 million deaths each year [1]. COPD is a leading cause of morbidity and mortality worldwide [4] and results in an economic and social burden which is substantial and increasing.

Asthma is also one of the leading causes of morbidity, mortality and economic burden worldwide [1]. According to the World Health Organization, the number of Asthma patients is 300 million and with its rising trends it is expected to increase to 400 million, by 2025 [5].

Taking into account the increasing prevalence of both Asthma and COPD, the morbidity and mortality they cause, and the increasing economic and social burden, it is crucial that both conditions should be treated in the most effective way.
Inhalers are the principle vehicles for the effective treatment of both Asthma and COPD. Delivery of respiratory drugs via inhalation achieves a high concentration in the airways, more rapid onset of action, and fewer systemic adverse effects than systemic delivery [6]. There are numerous options for inhalation devices and continuously improved technical features to better meet each patient's need. However, the effective drug delivery to the lungs depends highly on correctly performed inhalation maneuvers, making efficient training of the inhaler technique of paramount importance. Training on inhalation maneuvers is crucial for effective management of Asthma and COPD, is recommended by both GINA and GOLD guidelines, and in combination with frequent monitoring of the inhalation technique ensure effective control and optimal therapy for Asthma and COPD patients [4,6-10]. Data from literature report that as many as $25 \%$ of patients had never received verbal inhaler technique instruction [8],

*Corresponding author: Demosthenes Bouros, First Academic Department of Pneumonology, Medical School, University of Athens, Hospital for Diseases of the Chest "Sotiria", Messogion Ave 152, Athens 11527, Greece, Tel: +30-2107763557; E-mail: dbouros@med.uoa.gr, debouros@gmail.com

Received June 01, 2016; Accepted July 15, 2016; Published July 19, 2016

Citation: Bouros D, Evangeliou MN (2016) Critical Steps: A Non-Interventional Multicenter, Prospective, Observational Study on Critical Handling Errors with DP Use, in Asthma and COPD Patients. J Pulm Respir Med 6: 360. doi: 10.4172/2161105X.1000360

Copyright: (C) 2016 Bouros D, et al. This is an open-access article distributed under the terms of the Creative Commons Attribution License, which permits unrestricted use, distribution, and reproduction in any medium, provided the original author and source are credited. 
up to $85 \%$ of patients do not use their inhalers correctly [8], and that instructions of use usually derive from patient information leaflets (PILs) for inhaler users and not patient education by the physician, with consequences on correct inhaler use, treatment efficacy and subsequently Asthma/COPD control [7,11].

Given the influence of correct inhalation technique on drug delivery and efficacy, it is crucial to focus on assessment of device use and plan strategies to ensure effective use of inhaler devices when errors occur. Personal instructions and patient training on correct use of inhalation device minimize faulty device handling and promote treatment efficacy and disease control. In a study that evaluated the inhalation technique of experienced Asthma and COPD patients using the Diskus ${ }^{\circ}$, Handihaler ${ }^{\bullet}$ and Turbuhaler ${ }^{\circledR}$ inhalation devices it was reported that at least one critical error that influences drug delivery was observed for $34.5 \%$ of Diskus ${ }^{\circledast}$ users, $35 \%$ of Handihaler ${ }^{\circledast}$ users, and $43.5 \%$ of Turbuhaler ${ }^{\bullet}$ users [11]. In a 4 -week multicenter, randomized, parallel group trial that compared correct use of Diskus ${ }^{\oplus}$, Easyhaler ${ }^{\oplus}$, and Turbuhaler ${ }^{\circ}$, among 326 inhaler-naive Asthma patients, it was reported that during first visit the proportions of subjects using their devices correctly, after reading instructions from PILs, were $43 \%$ for Diskus ${ }^{\circ}$, $45 \%$ for Easyhaler ${ }^{\oplus}$, and $51 \%$ for Turbuhaler ${ }^{\circledR}[12]$. The corresponding proportions a month later, following 2 sets of patient education and training at 2 and 4 weeks, were $89 \%, 84 \%$ and $81 \%$ for Diskus ${ }^{\circ}$, Easyhaler ${ }^{\oplus}$, and Turbuhaler ${ }^{\circ}$ users respectively, indicating the need for training in inhalation technique, irrespective of device used. Another randomized crossover study that compared Diskus ${ }^{\circ}$ and Elpenhaler ${ }^{\circ}$ device use and included 113 COPD and Asthma patients naive to both inhalers has shown that after reading only PILs $16.8 \%$ of Diskus ${ }^{\oplus}$ and $35.4 \%$ of Elpenhaler ${ }^{\circledR}$ users made at least one critical error, while the respective percentages after first instruction by the trainer decreased at both patient groups, reaching $1.8 \%$ and $11.5 \%$ for Diskus ${ }^{\circ}$ and Elpenhaler ${ }^{\circ}$ users, respectively [13]. The value of training of inhalation technique is further confirmed by the results of another randomized crossover study that assessed the use of Diskus $\%$ Accuhaler ${ }^{\star}$ and Turbuhaler ${ }^{\bullet}$ devices, after PIL reading only and after inhaler education [14]. The results showed that the percentage of correct handling maneuvers and the percentage of patients achieving $100 \%$ of correct maneuvers increased significantly after inhaler education in both tested devices. Improvement in inhalation technique has also been observed in another study where it was reported that patients who had received previous instructions in inhalation technique had a $9 \%$ higher score than those who had not [15]. Improvements both on inhaler technique and respiratory symptoms of patients after patient instruction have been also reported in a single blind, randomized intervention study in which 48 patients who had been using a dry powder inhaler (DPI) for at least one month took part [16]. In this study, patients who had received instructions had a significantly greater reduction in the number of mistakes than the patients who did not. Moreover, the instructed patients also reported less dyspnea, suggesting that better inhalation technique facilitated disease control.

Apart from correct inhalation technique, patient preference and satisfaction on treatment can favor adherence to inhaled therapy and therefore improve treatment efficacy. The FSI-10 (Feeling of Satisfaction with Inhaler) questionnaire is designed to determine the ease of use and patient satisfaction in relation to different inhalers, irrespective of the drug used [17].

Treatment efficacy for both Asthma and COPD is evaluated by pulmonary function tests (i.e., spirometry) and symptom checks. Questionnaires such as the Asthma Control Questionnaire (ACQ) and the COPD Assessment Test (CAT) give further information concerning patient's status and facilitate better management of Asthma and COPD. ACQ is a test developed to measure the primary goals of Asthma management as identified by international guidelines $[18,19]$. The minimum clinically important difference is 0.5 . The COPD Assessment Test (CAT) is a patient-completed questionnaire assessing globally the impact of COPD (cough, sputum, dyspnea, and chest tightness) on health status. CAT appears to behave the same way across countries [20]. The minimum clinically important difference has been estimated to range between $2[21]$ to $3.76[22,23]$ points.

To date there are no studies assessing device use in COPD or Asthma patients in Greece, therefore the primary objective of this study was to assess the three most commonly used DPIs in the country (Diskus ${ }^{\oplus}$, Elpenhaler ${ }^{\oplus}$, Turbuhaler ${ }^{\circ}$ ) on critical errors that influence correct inhalation and drug uptake-delivery, in these patient groups.

\section{Patients and Methods}

\section{Patients}

We planned to enroll 870 diagnosed Asthma and COPD outpatients $\geq 18$ years of age ( 290 patients per device). Patients had to be naive to DPI use, able to understand study procedures, complete study informed consent form (ICF), comply with doctor's instructions and fill in the questionnaires of the study (ACQ, CAT, FSI-10).

Patients were excluded from the study if they were contraindicated according to Summary of Product Characteristics (SmPC) of assigned therapy, used oral corticosteroids, had an Asthma or COPD attack, had physical inability to use the selected inhalation device correctly, suffered from acute or chronic illness, or mental illness or neurodegenerative disease (i.e., Alzheimer's disease, depression, dementia, etc.) that could interfere with the conduct or completion of the trial, actively participated in another drug or device investigational study, did not sign ICF, and were either pregnant (women) or willing to become pregnant. The basic demographic and clinical characteristics of the study population are described in Tables 1 and 2 .

\section{Study design}

The present study was a multicenter, prospective, noninterventional, observational, open-label, parallel group study that was initially planned to include 58 sites (hospital and private pulmonary clinical sites). The study consisted of a three-month enrollment period, followed by a one-month treatment period. Each site had to enroll 15 Asthma or COPD patients during the study, assigned in groups of five, attributed to the three inhalation devices tested, namely Diskus ${ }^{\circ}$

\begin{tabular}{|c|c|c|c|c|}
\hline & \multicolumn{2}{|c|}{ Asthma patients $(\mathrm{N}=409)$} & \multicolumn{2}{|c|}{ COPD patients $(\mathrm{N}=346)$} \\
\hline & $\mathrm{N}$ & $\%$ & $\mathrm{~N}$ & $\%$ \\
\hline \multicolumn{5}{|l|}{ Gender } \\
\hline Male & 170 & 41.6 & 257 & 74.3 \\
\hline Female & 239 & 58.4 & 89 & 25.7 \\
\hline Age (mean $\pm \mathrm{SD}$ ) & \multicolumn{2}{|c|}{$49.4 \pm 17.2$} & \multicolumn{2}{|c|}{$64.9 \pm 11.0$} \\
\hline \multicolumn{5}{|l|}{ Smoking status } \\
\hline Smokers & 70 & 17.1 & 156 & 45.1 \\
\hline Ex-smokers & 88 & 21.5 & 165 & 47.7 \\
\hline Non-smokers & 251 & 61.4 & 25 & 7.2 \\
\hline \multicolumn{5}{|l|}{ Educational level } \\
\hline Illiterate & 13 & 3.2 & 12 & 3.5 \\
\hline Primary school & 84 & 20.5 & 133 & 38.4 \\
\hline Secondary school & 60 & 14.7 & 75 & 21.7 \\
\hline High school & 142 & 34.7 & 81 & 23.4 \\
\hline University & 110 & 26.9 & 45 & 13.0 \\
\hline
\end{tabular}

Table 1: Basic demographic characteristics of study patients at baseline visit. 
Citation: Bouros D, Evangeliou MN (2016) Critical Steps: A Non-Interventional, Multicenter, Prospective, Observational Study on Critical Handling Errors with DPI Use, in Asthma and COPD Patients. J Pulm Respir Med 6: 360. doi:10.4172/2161-105X.1000360

Page 3 of 8

\begin{tabular}{|c|c|c|c|c|}
\hline & \multicolumn{2}{|c|}{$\begin{array}{l}\text { Asthma patients } \\
(\mathrm{N}=409)\end{array}$} & \multicolumn{2}{|c|}{ COPD patients $(\mathrm{N}=346)$} \\
\hline & $\mathbf{N}$ & $\%$ & $\mathbf{N}$ & $\%$ \\
\hline \multicolumn{5}{|l|}{ Pulmonary function } \\
\hline FEV1 (It) (mean \pm SD) & $2.4 \pm 0.9$ & & $1.7 \pm 0.8$ & \\
\hline FEV1 \% pred (mean \pm SD) & $77.9 \pm 18.3$ & & $58.2 \pm 17.5$ & \\
\hline FEV1/FVC $($ mean $\pm S D)$ & $76.4 \pm 12.1$ & & $67.0 \pm 14.3$ & \\
\hline \multicolumn{5}{|l|}{ Asthma control } \\
\hline Controlled & 80 & 19.6 & - & - \\
\hline Partly controlled & 238 & 58.2 & - & - \\
\hline Uncontrolled & 91 & 22.2 & - & - \\
\hline \multicolumn{5}{|c|}{ Classification of severity of airflow limitation } \\
\hline GOLD 1 & - & - & 71 & 20.5 \\
\hline GOLD 2 & - & - & 155 & 44.8 \\
\hline GOLD 3 & - & - & 97 & 28 \\
\hline GOLD 4 & - & - & 23 & 6.6 \\
\hline \multicolumn{5}{|c|}{ Combined COPD assessment } \\
\hline Group A & - & - & 75 & 21.7 \\
\hline Group B & - & - & 130 & 37.6 \\
\hline Group C & - & - & 77 & 22.3 \\
\hline Group D & - & - & 64 & 18.5 \\
\hline
\end{tabular}

Table 2: Basic clinical characteristics of study patients at baseline visit.

Elpenhaler ${ }^{\circledR}$ and Turbuhaler ${ }^{\circledR}$. Eligible patients were assigned to the appropriate inhaled therapy according to the doctor's opinion in a consecutive manner.

At baseline visit (day 0), spirometry was performed to all selected patients, who were then prescribed inhaled therapy (medication via Diskus $^{\circledR}$, Elpenhaler ${ }^{\circledR}$ and Turbuhaler ${ }^{\circledR}$ ) according to established clinical practice [24]. The physicians demonstrated to each patient the correct, according to device, inhalation technique, in 8 distinct steps which were set by a device-specific 8 step checklist. Then the patient was asked to perform the inhalation maneuvers previously shown to him. The device-specific 8 step checklists used for Diskus ${ }^{\oplus}$, Elpenhaler ${ }^{\bullet}$ and Turbuhaler ${ }^{\oplus}$ are described in Tables 3-5. The physician observed the patient having his/her first administration and checked the steps that were performed successfully. Additionally, at baseline visit, each patient had to complete a disease-specific questionnaire (Asthma Control Questionnaire (ACQ) for Asthma patients and COPD Assessment Test (CAT) for COPD patients) to record patient's perspective about his/ her condition. The ACQ is valid for measuring Asthma control and has strong measurement properties for use both in clinical practice and research. ACQ scores range from $0-6$ (higher is worse) $[6,19]$. A score of 0.0-0.75 is classified as well-controlled Asthma; 0.75-1.5 as a 'grey zone'; and $>1.5$ as poorly controlled Asthma. The ACQ score is calculated as the average of 5,6 or 7 items: all versions of the ACQ include five symptom questions; ACQ-6 includes reliever use; and in ACQ-7, a score for pre-bronchodilator FEV is averaged with symptom and reliever items. ACQ is a numerical "Asthma control" tool, which is very sensitive to changes in Asthma symptom control. CAT is a simple and easy-to-use questionnaire that distinguishes between patients of different degrees of COPD severity and appears to behave the same way across countries [20].

An interim phone call interview was performed by the physician 15 days after baseline visit in order to ascertain whether a serious adverse event or a problem with inhalation device use occurred at the preceding 15 days period. In case a serious problem/adverse event was reported, an emergency visit was scheduled and all appropriate measures for patient's safety were taken.

At final visit (day 30), patients were asked to attend along with

To open your device, hold the outer case in one hand and put the thumb 1 of your other hand on the thumb grip. Push your thumb away from you as far as it will go. You will hear a click.

2 Hold your device with the mouthpiece towards you (in a horizontal position)

3 Slide the lever away from you as far as it will go until you hear a click.

4 Exhale to residual volume.

5 Exhale away from mouthpiece.

6 Mouthpiece between teeth and lips.

7 Inhale forcefully and deeply.

8 Hold breath for about 5-10 seconds.

Table 3: Diskus ${ }^{\circledR}$ 8-step checklist.

1 Open storage compartment, take a strip and close compartment again.

2 Uncover the mouthpiece completely from its protective cover. Unlock and

2 push the mouthpiece backwards as to reveal the supporting surface. Place the strip correctly on the attachment point of the supporting

3 surface, close the mouthpiece and pull away the protruding end of the strip until it is detached.

4 Exhale to residual volume.

5 Exhale away from mouthpiece.

6 Mouthpiece between teeth and lips.

7 Inhale deeply

8 Hold breath for about 5-10 seconds.

Table 4: Elpenhaler ${ }^{\circledR}$ 8-step checklist.

1 Remove the cap from the inhaler.

2 Hold your inhaler upright with the red grip at the bottom.

Turn the red grip as far as it will go in one direction. Then turn it as far as it will go in the other direction. You should hear a click sound.

4 Exhale to residual volume.

5 Exhale away from mouthpiece.

6 Mouthpiece between teeth and lips.

7 Inhale forcefully and deeply.

8 Hold breath for about 5-10 seconds.

Table 5: Turbuhaler ${ }^{\circledR}$ 8-step checklist.

their inhalation device. Initially, patients were asked to fill in two questionnaires; the disease-specific ACQ or CAT questionnaire and the FSI-10 questionnaire in which patient's personal opinion on the inhalation device used was recorded [25,26]. The FSI-10 is a self-report instrument containing 10 questions, each with 5 possible responses on a 5-point Likert scale (very, fairly, somewhat, not very, hardly at all) scored from 5 to 1 , respectively (maximum total score, 50). It assesses the level of satisfaction of patients with the inhaler and includes items on ease or difficulty of use, portability, and usability. FSI-10 is easy to understand and complete and able to identify differences in patient satisfaction with the different inhalers.

Adverse events (AEs) were constantly reported during total study period. All patients gave their written informed consent before entering the study. The study was conducted in accordance with the Declaration of Helsinki and Good Clinical Practice guidelines and approved by the ethics committee of the participating centers (hospital sites).

\section{Assessments}

The assessment of devices (Diskus ${ }^{\oplus}$, Elpenhaler ${ }^{\circledR}$ and Turbuhaler ${ }^{\circledast}$ ) on critical errors that could influence correct inhalation and drug uptake-delivery, in Asthma and COPD patients, was the primary objective of the study. For this reason, the percentage of Asthma or COPD patients with good/adequate use of their inhaler device at baseline and final were calculated. Good use of the device was demonstrated 
Citation: Bouros D, Evangeliou MN (2016) Critical Steps: A Non-Interventional, Multicenter, Prospective, Observational Study on Critical Handling Errors with DPI Use, in Asthma and COPD Patients. J Pulm Respir Med 6: 360. doi:10.4172/2161-105X.1000360

Page 4 of 8

by the score of the device-specific-8-step checklist (Tables 2-4). Each successfully performed step scored one point, whereas a step which was not performed successfully or it was omitted scored zero. Good use was demonstrated if patient executed correctly all 8 steps of the checklist. Adequate use was demonstrated if patient performed at least the 5 (out of 8) steps that influence mostly correct inhalation and drug uptakedelivery (steps in checklists marked in bold).

Moreover, change in questionnaire scores (CAT, ACQ) between baseline and final visit were recorded as well as FSI-10 score, spirometric, safety, clinical and demographic data.

\section{Statistical analyses}

Data were analyzed using SPSS version 21.0 statistical package. Descriptive statistical analysis was used for demographic data. Normality of values was checked by one sample Kolmogorov-Smirnov test. If distribution was asymmetric, variables were presented as median, mode or range. Scores were expressed as arithmetic means. Total scores were given as (mean \pm standard deviation (SD)). If applicable, variables were also presented as frequencies and/or percentage. Bivariate correlations were checked by the appropriate statistical tests. Differences in scores between devices were analyzed by non-parametric Mann Whitney-U test. Comparisons of the mean scores between devices were made by independent samples t-test. Oneway ANOVA with post hoc Bonferroni corrections was also used for comparisons of group scores. A $\mathrm{P}<0.05$ was considered to indicate statistical significance.

\section{Results}

\section{Patient disposition}

We enrolled 755 patients (346 COPD, 409 Asthma) from 54 clinical sites and 739 (338 COPD, 401 Asthma) patients completed the study as per protocol. Study diagram and patient's disposition per device per visit are shown in Figure 1.

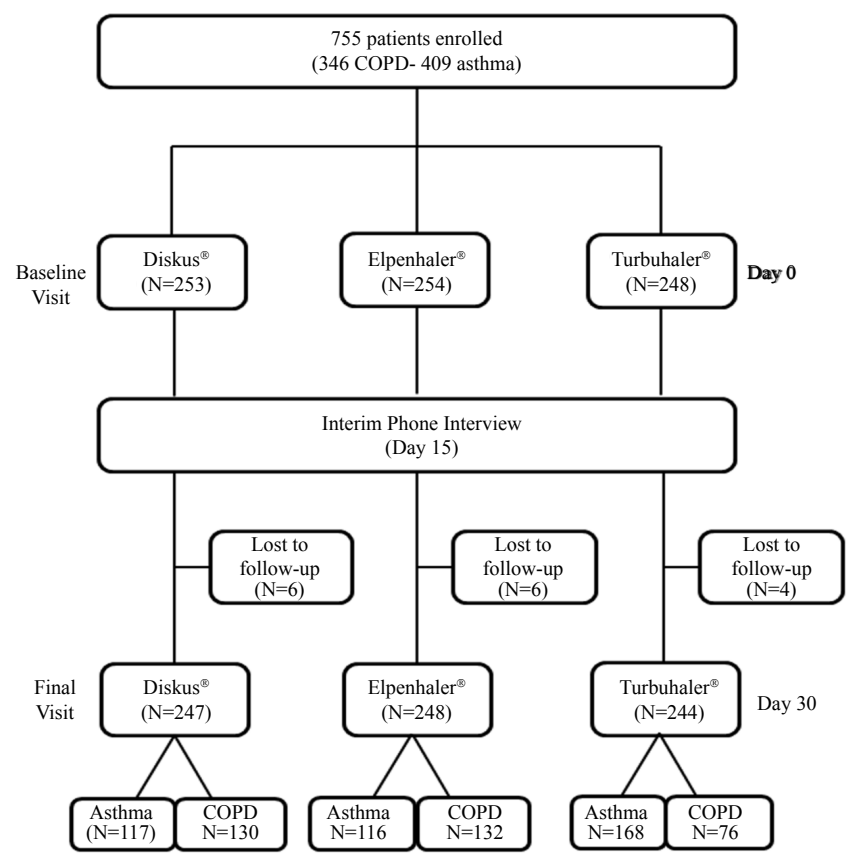

Figure 1: Study diagram and patient's disposition.

\section{Assessment of device use}

At baseline visit, device use was assessed as good in $75.2 \%, 75.2 \%$ and $71.0 \%$ of Diskus ${ }^{\oplus}$, Elpenhaler ${ }^{\oplus}$ and Turbuhaler ${ }^{\oplus}$ users, respectively, and adequate in $78.7 \%$ of Diskus ${ }^{\circ}$ users, $79.5 \%$ of Elpenhaler ${ }^{\circ}$ users, and $74.2 \%$ of Turbuhaler ${ }^{\circ}$ users (Figure 2).

At the last visit, Diskus ${ }^{\circ}$ use was assessed as good in $75.2 \%$ and $80.6 \%$ of Diskus ${ }^{\circ}$ users at baseline and final visits respectively, while the percentage of Diskus ${ }^{\circledR}$ users performing adequately the critical inhalation maneuvers rose from $78.7 \%$ to $84.6 \%$ between baseline and final visit. The percentage of Elpenhaler ${ }^{\oplus}$ users performing successfully all steps rose from $75.2 \%$ to $87.5 \%$, while the percentage of Elpenhaler users performing adequately the critical inhalation maneuvers rose from $79.5 \%$ to $92.7 \%$. Turbuhaler ${ }^{\circ}$ use was assessed as adequate in $74.2 \%$ during baseline visit and in $75.4 \%$ of patients during last visit. Good Turbuhaler use was demonstrated in $71.0 \%$ and $71.7 \%$ of patients at baseline and final visit respectively (Figures 2 and 3).

The change in the percentage of patients performing successfully all steps or critical steps per device, between baseline and final visit is briefly described in Figure 4. More specific, the percentage of Diskus ${ }^{\oplus}$ users performing successfully all steps or the critical steps of the inhalation maneuvers, increased by $3.2 \%$ and $3.6 \%$ respectively, one month after first inhalation attempt. Also, a month after first inhalation through Elpenhaler ${ }^{\circledR}$, the percentage of patients performing successfully all steps or at least the critical steps of the inhalation maneuvers, increased by $10.5 \%$ and $11.3 \%$ respectively, showing an overall improvement

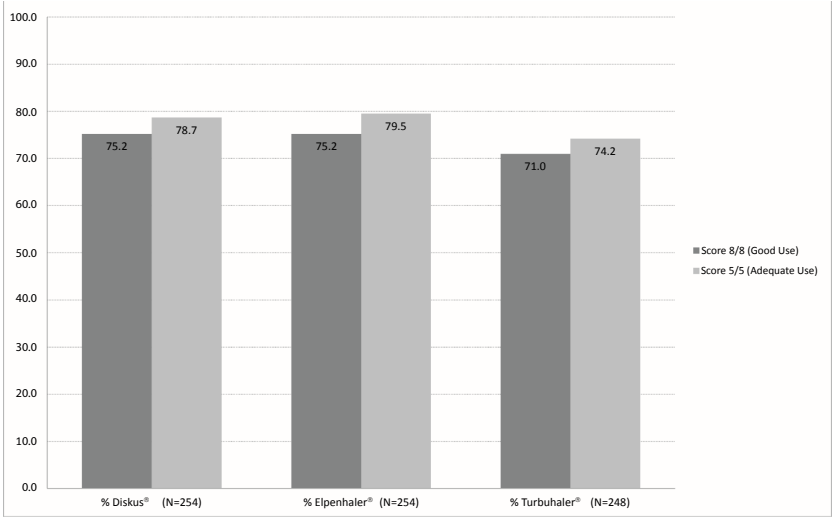

Figure 2: Percentages of COPD and asthma patients with good/adequate device use at baseline (Day 0).

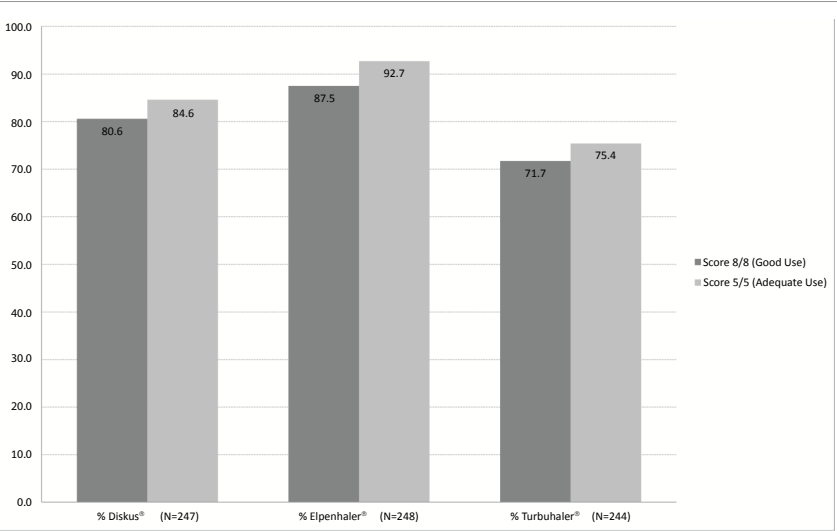

Figure 3: Percentages of COPD and asthma patients with good/adequate device use at final visit (Day 30). 


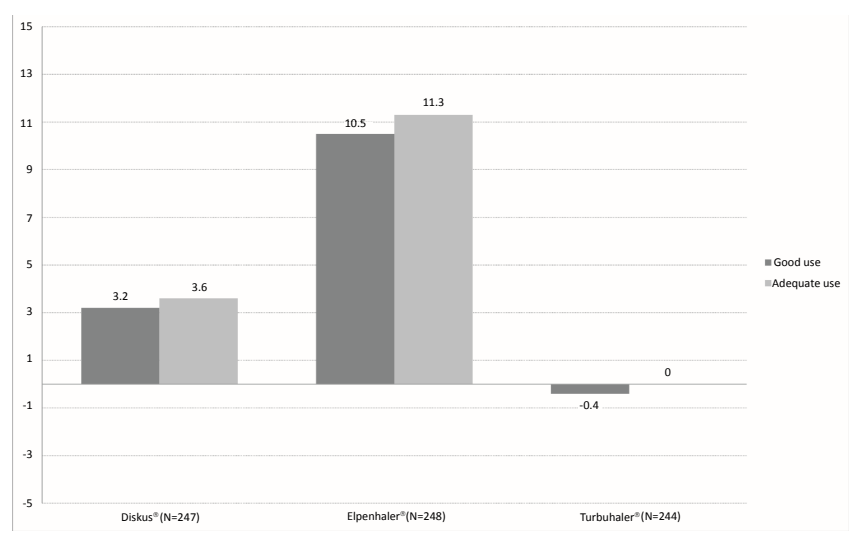

Figure 4: Change percentage in good/adequate device use between final and baseline visits, per device.

of inhalation technique over time. There was no significant change observed in Turbuhaler ${ }^{\circledR}$ users at final visit.

The overall improvement of inhalation technique over time is further demonstrated by the decrease of the total number of critical errors (i.e., critical steps not successfully performed/not performed at all) reported for each device, which is depicted in Figure 5. More specific, the number of critical errors recorded for Diskus ${ }^{\oplus}$ use at baseline and final visit were 92 and 61 respectively, corresponding to error decrease from $7.3 \%$ to $4.9 \%$. Moreover, the total number of critical errors observed in baseline visit for Elpenhaler ${ }^{\oplus}$ was 93 , which corresponds to a 7\% error on total critical steps performed via Elpenhaler ${ }^{\bullet}$ at baseline visit, while the error rate at final visit decreased to $2.5 \%$, corresponding to a total of 31 critical errors observed. The respective number of critical errors for Turbuhaler ${ }^{\circledR}$ at baseline and final visit, was 106 and 86 respectively, corresponding to a small decrease at error rates (from $8.5 \%$ to $7 \%$ ). Among the three devices tested, Elpenhaler ${ }^{\circledR}$ was the inhalation device with the lowest error rates on critical steps observed, both at baseline and final visit.

A more detailed view of the errors recorded per step, per device at baseline and final visits is depicted in Table 6, where the general improvement in inhalation technique at final visit is evident.

\section{Questionnaires}

Figure 6 shows the FSI-10 scores reported following a 30-day experience with each inhalation device. The mean FSI-10 scores for Diskus ${ }^{\oplus}$, Elpenhaler ${ }^{\oplus}$, and Turbuhaler ${ }^{\oplus}$, were 41.6, 44.0, and 41.8 respectively, indicating that all patients, irrespective of device used, were at least fairly satisfied. Moreover, the differences observed between Elpenhaler ${ }^{\circledR}$ and Turbuhaler $^{\oplus}$ or Diskus ${ }^{\oplus}$ scores were statistically significant $(\mathrm{p}<0.001$ and $\mathrm{p}=0.005$ respectively), suggesting that Elpenhaler ${ }^{\circledR}$ may be associated with greater patient satisfaction, as compared to Turbuhaler ${ }^{\circledast}$ or Diskus ${ }^{\oplus}$.

The difference between last and baseline visit in ACQ score for Asthma patients, is depicted in Figure 7. More specific, a statistically significant decrease in ACQ score $(\mathrm{p}<0.001)$ between last visit and baseline has been reported for all devices, with Elpenhaler ${ }^{\oplus}$ recording the largest decrease (-1.40). However, the difference in ACQ score did not differ significantly among devices. The decrease in ACQ observed was not only statistically but also clinically significant for all devices, since the minimum clinically important difference is -0.5 , indicating improved Asthma control [27]. In addition, a significant correlation between $\triangle \mathrm{ACQ}$ and total FSI-10 score among Asthma patients has

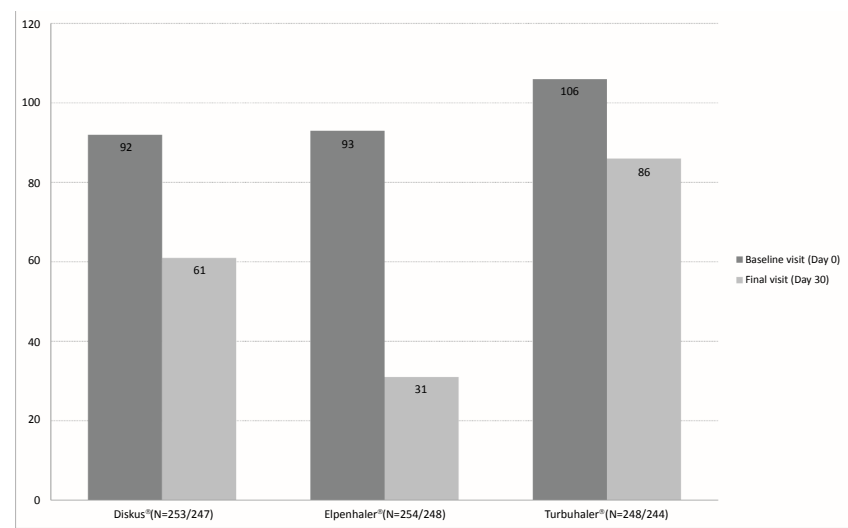

Figure 5: Total number of critical errors per device per visit.

\begin{tabular}{|c|c|c|c|c|c|c|}
\hline \multirow[b]{2}{*}{ Steps } & \multicolumn{2}{|c|}{ Diskus $^{\circledR}$} & \multicolumn{2}{|c|}{ Elpenhaler $^{\circledR}$} & \multicolumn{2}{|c|}{ Turbuhaler $^{\circledR}$} \\
\hline & $\begin{array}{c}\text { V1 } \\
(\mathrm{N}=253)\end{array}$ & $\begin{array}{c}\text { V2 } \\
(\mathrm{N}=247)\end{array}$ & $\begin{array}{c}\mathrm{V} 1 \\
(\mathrm{~N}=254)\end{array}$ & $\begin{array}{c}\text { V2 } \\
(\mathrm{N}=248)\end{array}$ & $\begin{array}{c}V 1 \\
(N=248)\end{array}$ & $\begin{array}{c}\text { V2 } \\
(\mathrm{N}=244)\end{array}$ \\
\hline 1 & 8 & 5 & 9 & 3 & 4 & 3 \\
\hline 2 & 23 & 14 & 11 & 3 & 18 & 16 \\
\hline 3 & 17 & 7 & 25 & 7 & 37 & 24 \\
\hline 4 & 30 & 14 & 33 & 13 & 31 & 27 \\
\hline 5 & 32 & 29 & 37 & 14 & 37 & 38 \\
\hline 6 & 12 & 11 & 9 & 5 & 11 & 15 \\
\hline 7 & 12 & 6 & 11 & 4 & 10 & 5 \\
\hline 8 & 21 & 14 & 9 & 13 & 31 & 16 \\
\hline $\begin{array}{l}\text { Total } \\
\text { errors }\end{array}$ & 155 & 100 & 144 & 62 & 179 & 144 \\
\hline $\begin{array}{l}\% \\
\text { Difference }\end{array}$ & \multicolumn{2}{|c|}{-35.5} & \multicolumn{2}{|c|}{-56.9} & \multicolumn{2}{|c|}{-19.6} \\
\hline p & \multicolumn{2}{|c|}{$<0.05$} & \multicolumn{2}{|c|}{$<0.05$} & \multicolumn{2}{|c|}{$<0.05$} \\
\hline
\end{tabular}

Table 6: Number of errors reported at baseline (V1) and final visit (V2) per device per step.

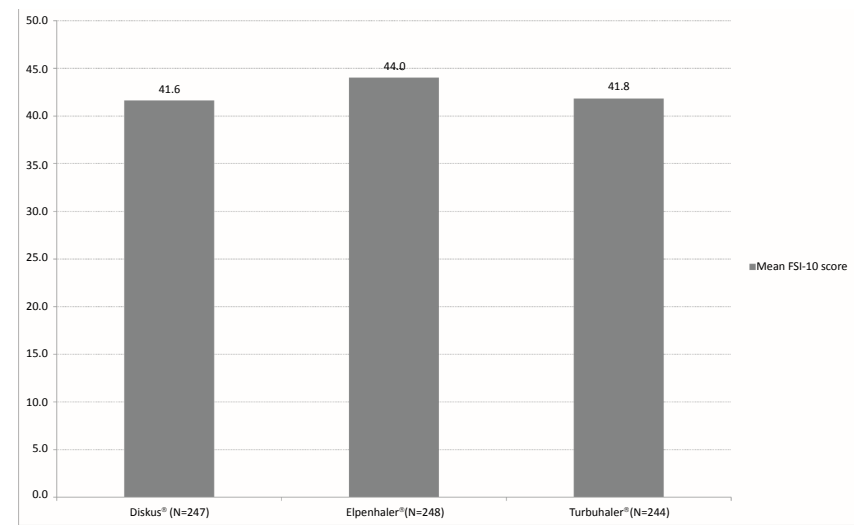

Figure 6: Mean FSI-10 score per device.

been observed $(p=0.019)$, implying that patients who were more satisfied from their device had a better perspective on their health status or vice versa.

The difference between last visit and baseline visit, as far as the CAT score in COPD patients is concerned, is depicted in Figure 8. CAT score decreased between final and baseline visit by $4.94,6.37$ and 4.07 points for Diskus ${ }^{\oplus}$, Elpenhaler ${ }^{\oplus}$ and Turbuhaler ${ }^{\oplus}$ users respectively, a clinically 


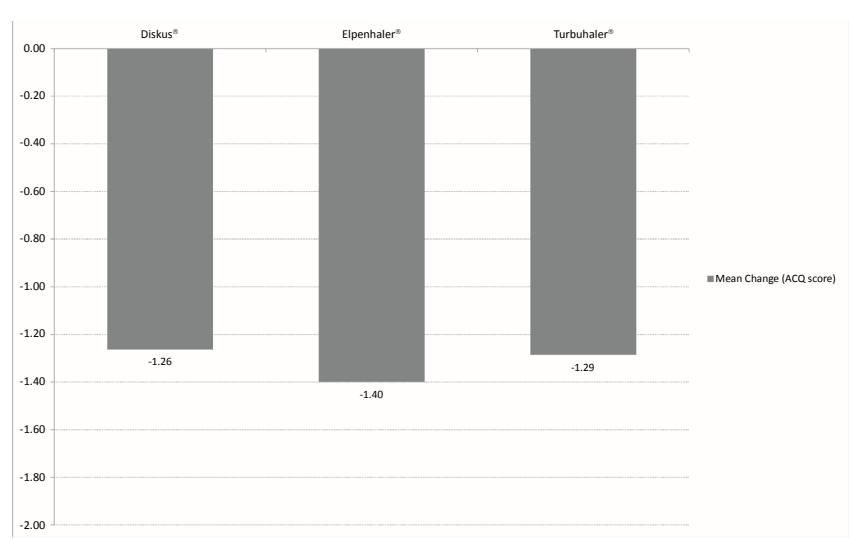

Figure 7: Mean change in ACQ score per device.

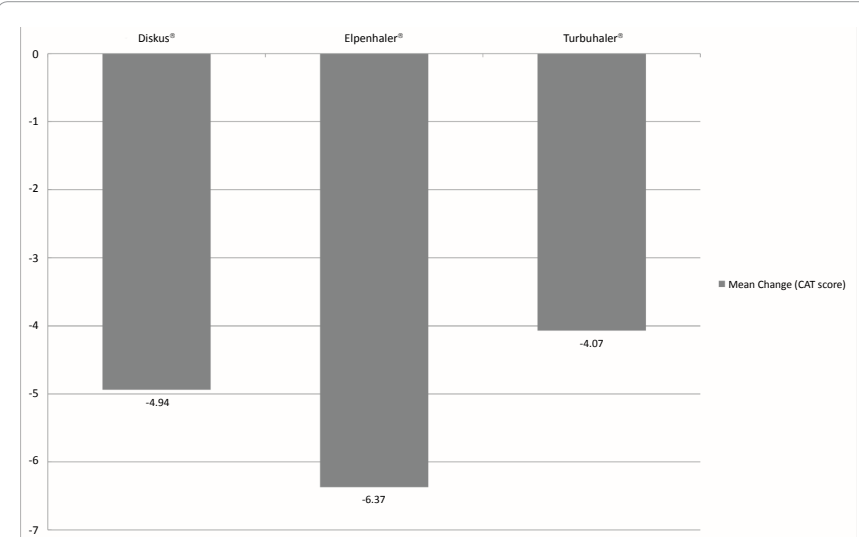

Figure 8: Mean change in CAT score per device.

significant change for all devices, that indicates improved viewpoint on the perceived impact of COPD in patients' life. $\triangle \mathrm{CAT}$ comparison of Elpenhaler ${ }^{\circledR}$ and Turbuhaler ${ }^{\circledR}$ was found to be statistically significant ( $\mathrm{p}=0.016$ ), whereas $\triangle \mathrm{CAT}$ comparison of Elpenhaler ${ }^{\bullet}$ and Diskus ${ }^{\circledR}$ did not find statistically significant differences $(\mathrm{p}=0.127)$. Also, a significant correlation was found between mean $\triangle \mathrm{CAT}$ total score and mean FSI10 total score $(\mathrm{p}=0.001)$ in COPD patients, implying that patients who were more satisfied from their device had a better perspective on their health status.

\section{Spirometry}

There was no significant difference for $\triangle \mathrm{FEV}_{1}$ between final and baseline visits for Diskus ${ }^{\oplus}$, Elpenhaler ${ }^{\oplus}$, or Turbuhaler ${ }^{\oplus}$ patient groups ( $p>0.05)$ and there was an overall improvement in mean $\mathrm{FEV}_{1}$ for both COPD and Asthma patients following one-month treatment. The change in mean $\mathrm{FEV}_{1}$ between final and baseline visit was found to be significant both for Asthma (0.3 lt $\pm 0.4, \mathrm{p}<0.001)$ and COPD (0.15 lt $\pm 0.57, \mathrm{p}<0.001)$ patients. As far as AEs is concerned, the AEs reported were rare and mild in intensity in all used devises. The most common adverse events reported were hoarseness, tremor and stomatitis. The difference in FEV , between final and baseline visit was also found to be strongly correlated both with $\triangle \mathrm{ACQ}(\mathrm{p}<0.001)$ and with $\triangle \mathrm{CAT}$ $(\mathrm{p}<0.001)$ in Asthma and COPD patients, respectively.

\section{Discussion}

This is the first DPI usability study in Asthma and COPD patients in Greece. The study was observational in design to depict real-life conditions. All patients were DPI-naive to exclude bias from prior use of another DPI. Correct use of each device was demonstrated to each patient by the doctor prior to first administration and evaluated by the use of 8-step device specific checklists.

Our results showed that physical demonstration of correct inhalation maneuvers for each device prior to first administration, leads to high percentages of adequate use for all tested devices (Diskus ${ }^{\oplus}$, Elpenhaler ${ }^{\circledR}$ and Turbuhaler ${ }^{\circledR}$ ), both at first use and a month later, ensuring optimal efficacy of the inhaled therapy, and further confirming that demonstration of correct use and training are of paramount importance [4,6-10]. Among tested inhalers, Elpenhaler was the device with the lowest error rates on critical steps observed, both at baseline and final visit, and the highest score in the Feeling of Satisfaction with Inhaler Questionnaire.

Physical demonstration of correct inhalation technique prior to first administration resulted in more than $70 \%$ of patients performing all inhalation maneuvers correctly from first use. The percentage of good use at first demonstration for Diskus ${ }^{\oplus}$ was $75.2 \%$, for Elpenhaler ${ }^{\otimes}$ was $75.2 \%$ and for Turbuhaler ${ }^{\circ}$ was $71.0 \%$, percentages that are significantly higher than those observed in another study (43\% for Diskus $^{\star}$ and $51 \%$ for Turbuhaler ${ }^{\star}$ ) in which first patient demonstration was performed after PIL reading [12]. This finding suggests that physical demonstration of correct use is more effective than simple PIL reading. In another study, it has been shown that after a single instruction $74 \%$ of patients using the Diskus ${ }^{\circ}$ device and $32 \%$ the Turbuhaler ${ }^{\circ}$ device were able to use their devices correctly [28].

Patient performance on inhalation technique improved after one month, with improvement being more evident in Elpenhaler ${ }^{\circledR}$ users and least evident in Turbuhaler ${ }^{\circ}$ users. More specific, during final visit almost $85 \%$ of Diskus ${ }^{\infty}, 93 \%$ of Elpenhaler ${ }^{\circ}$, and $75 \%$ of Turbuhaler ${ }^{\circ}$ users did not make any critical errors. Improvement of inhalation technique over a four-week period, observed in our study, is in line with other studies $[12,16]$.

Improvement of inhalation technique and minimization of critical errors lead to more effective drug delivery and therefore symptom control [4,6-10]. Our results are in agreement with this, since statistically and clinically significant improvements have been observed both for ACQ and CAT questionnaires for all devices tested.

As far as the ACQ questionnaire is concerned, the differences between visits recorded for Diskus ${ }^{\oplus}$, Elpenhaler ${ }^{\oplus}$ and Turbuhaler ${ }^{\circ}$ were $-1.26,-1.40$, and -1.29 respectively. The former differences exceed the minimum clinically important difference for ACQ, which was estimated at -0.5 points [27]. The difference in ACQ score did not differ significantly among devices.

The mean change recorded in CAT score between final and baseline visits was 4.94 for Diskus ${ }^{\oplus}, 6.37$ for Elpenhaler ${ }^{\oplus}$, and 4.07 for Turbuhaler ${ }^{\star}$, suggests that during final visit all patients had an improved viewpoint on the perceived impact of COPD on their life. The former changes are also clinically important since the minimum clinically important difference has been reported to range between 2-3.76 points [21-23].

As far as patient's feeling of satisfaction from device use is concerned, which was reflected in numbers through the FSI-10 questionnaire, it was found that all patients were at least fairly satisfied by their inhalation devices, justifying pulmonologists' selection of device according to patient profile and needs. FSI-10 score for Elpenhaler ${ }^{\bullet}$ was significantly higher than the corresponding scores of Diskus ${ }^{\bullet}$ and Turbuhaler ${ }^{\bullet}$. The latter findings are in agreement with recent publications $[29,30]$ concerning assessment of patient's feeling of satisfaction from Diskus ${ }^{\circledR}$, 
Elpenhaler ${ }^{\circledast}$ and Turbuhaler ${ }^{\circledast}$ in Greek COPD $(\mathrm{N}=517)$ and Asthma $(\mathrm{N}=523)$ patients, where mean total scores were similar and ranking of devices according to patient's feeling of satisfaction was the same (Elpe nhaler $^{\circledR}>$ Turbuhaler $^{\circledR}>$ Diskus $^{\circledast}$ ) [26]

The improvements presented above in both ACQ and CAT scores along with the scores of FSI-10 questionnaires suggest that adherence to therapy in both COPD and Asthma patients may be high in these groups of patients. Also, significant correlations have been observed between $\triangle$ ACQ and FSI-10 ( $\mathrm{p}=0.019)$, and $\triangle \mathrm{CAT}$ and FSI-10 scores ( $\mathrm{p}=0.001$ ), suggesting that patients who have an improved perspective of their health status are more satisfied by their inhalers and vice versa. The improved viewpoint on their condition is further confirmed by spirometric data, where statistically significant and clinically important $\mathrm{FEV}_{1}$ changes have been observed in both COPD and Asthma patients [31-34]. The latter is in agreement with recent bibliographic data that report positive correlations between satisfaction from inhaler devices with improved adherence and clinical outcomes [1].

Among the devices tested, Elpenhaler ${ }^{\circledR}$ was the device with the least error rates on critical steps observed, at both visits. The error rates observed for Elpenhaler ${ }^{\oplus}$ at baseline and final visits were $7.0 \%$ and $2.5 \%$ respectively, indicating that the possibility of making critical errors that influence correct inhalation and drug delivery is extremely low. Also, Elpenhaler is associated with greater patient satisfaction as compared to Diskus ${ }^{\oplus}$ and Turbuhaler ${ }^{\oplus}$ devices. Elpenhaler ${ }^{\circledast}$ is a relatively new inhalation device which was launched in the Greek market in 2006 and in the rest European countries in 2011, therefore there do not exist usability data from studies of similar design, in order to make direct comparisons.

Our study presents with some limitations. Firstly, the study is not randomized in design in order to simulate real-life conditions and therefore a device selection bias may be implied; however, the high FSI10 scores documented for all patient groups in our study indicate that assignment of devices was made according to patient profile and needs (current clinical practice) and not according to physician's special preferences. Secondly, in this study errors in inhalation maneuvers were recorded by utilizing device-specific checklists that were designed according to approved SmPCs and PILs. The latter provides an objective way of assessing device use that could be followed hereinafter on one hand, but on the other hand does not leave space for direct comparisons with other studies.

In conclusion, the study shows that physical demonstration of correct inhalation technique prior to first use, leads to minimization of critical errors during administration of an inhaled therapy and subsequently more effective disease control. Better symptom control was verified by the clinically significant changes reported for ACQ and CAT scores and spirometry data for all tested devices. The high FSI-10 scores reported for all devices tested indicate correct physician's judgment on which inhaler better meets each patient needs. Improvements in ACQ and CAT scores and high FSI-10 scores reported suggest adherence to therapy and more effective disease management. Elpenhaler ${ }^{\circledR}$ was the device with the lowest error rates and the highest FSI-10 score reported among the devices tested (Diskus ${ }^{\otimes}$ and Turbuhaler ${ }^{\circledR}$ ), suggesting that this recently developed inhaler is a reasonable and useful addition in the armamentarium of inhaled therapies for Asthma and COPD patients.

\section{Acknowledgements}

We would like to thank all pneumonologists, members of the Critical Steps study group for their participation in the conduct of the study: Adamidis Vasileios, Antoniadou Maria, Zakesti Stavroula, Thomoglou Eleni, Kapetangiorgis
Athanasios, Karipidis Efstathios, Kosma Alexandra, Mermigkas Konstantinos, Xafenias Athanasios, Oikonomidis Petros, Papadeli-Kourtidou Chrysoula, Papandreou Athanasios, Pechlivanidis Theofilos, Michailopoulos Pavlos Samiou Maria, Spyratos Dionisios, Tzelepi Vasiliki, Titopoulos Iraklis, Tselepis Elias, Tsiboukelis loannis, Charitopoulos Konstantinos, Adamou Eleni, Vlachou Athina,Vrouvakis Eleftherios, Gizopoulou Evangelia, Dimakou Aikaterini, Zacharis George, Kainis Elias, Kalfountzos George, Karianou Evgenia, Katsoni Athanasia, Komis Michail, Kotantoula Georgia, Lambropoulos Lambros, Maragkos Ioannis, Marosis Konstantinos, Michalopoulou Penelope, Xifteri Areti, Panagoulias Vasilios, Papadaki Anastasia, Papalexatos Dionisios, Papanikolaou loanna, Politis loannis Rovina Nikoletta, Savva Irene, Samartzi Iliana, Simiakakis Michail, Sfakianoudis Georgios, Tzagkaraki Aikaterini, Tsarouchis Georgios, Chouliara Konstantina, and Christou Konstantinos.

Special thanks to Dr. Konstantinos Kostikas for helping in the design and conduct of the study (Konstantinos Kostikas is a Novartis employee since January 01, 2015; he was not a Novartis employee during the design and conduction of the study).

\section{Author Disclosure Statement}

Prof. Demosthenes Bouros has received lecture fees from Boehringer Ingelheim, Roche and Bayer, and his department has been supported from GSK, Elpen Pharmaceutical Co. Inc., Novartis and Chiesi. Dr Mina Evangeliou is an employee of Elpen Pharmaceutical Co. Inc.

\section{References}

1. Mäkelä MJ, Backer V, Hedegaard M, Larsson K (2013) Adherence to inhaled therapies, health outcomes and costs in patients with asthma and COPD. Respir Med 107: 1481-1490.

2. Zervas E, Loukides S, Kostikas K, Bakakos P, Tzortzaki E, et al. (2012) Asthma and asthma-like symptoms in Greece. The Greece asthma national prevalence survey. Eur Respir J 40: 3936.

3. Tzanakis N, Anagnostopoulou U, Filaditaki V, Christaki P, Siafakas N et al (2004) Prevalence of COPD in Greece. Chest 125: 892-900.

4. http://www.goldcopd.it/materiale/2015/GOLD_Report_2015.pdf

5. Pawankar R (2014) Allergic diseases and asthma: a global public health concern and a call to action. World Allergy Organ J 7: 12.

6. Global Initiative for Asthma (2015) Global Strategy for Asthma Management and Prevention.

7. Melani AS (2007) Inhalatory therapy training: a priority challenge for the physician. Acta Biomed 78: 233-245.

8. Lavorini F, Magnan A, Dubus JC, Voshaar T, Corbetta L, et al. (2008) Effect of incorrect use of dry powder inhalers on management of patients with asthma and COPD. Respir Med 102: 593-604

9. Capstick TG, Clifton IJ (2012) Inhaler technique and training in people with chronic obstructive pulmonary disease and asthma. Expert Rev Respir Med 6: 91-101.

10. Ninane V, Brusselle GG, Louis R, Dupont L, Liistro G, et al. (2014) Usage of inhalation devices in asthma and chronic obstructive pulmonary disease: a Delphi consensus statement. Expert Opin Drug Deliv 11: 313-323.

11. Melani AS, Bonavia M, Cilenti V, Cinti C, Lodi M, et al. (2011) Inhaler mishandling remains common in real life and is associated with reduced disease control. Respir Med 105: 930-938.

12. Rönmark E, Jögi R, Lindqvist A, Haugen T, Meren M, et al. (2005) Correct use of three powder inhalers: comparison between Diskus, Turbuhaler, and Easyhaler. J Asthma 42: 173-178.

13. van der Palen J, van der Valk P, Goosens M, Groothuis-Oudshoorn K, BrusseKeizer M (2013) A randomised cross-over trial investigating the ease of use and preference of two dry powder inhalers in patients with asthma or chronic obstructive pulmonary disease. Expert Opin Drug Deliv 10: 1171-1178.

14. Serra-Batlles J, Plaza V, Badiola C, Morejón E (2002) Patient perception and acceptability of multidose dry powder inhalers: a randomized crossover comparison of Diskus/Accuhaler with Turbuhaler. J Aerosol Med 15: 59-64.

15. van der Palen J, Klein JJ, Kerkhoff AH, van Herwaarden CL (1995) Evaluation of the effectiveness of four different inhalers in patients with chronic obstructive pulmonary disease. Thorax 50: 1183-1187.

16. Verver S, Poelman M, Bögels A, Chisholm SL, Dekker FW (1996) Effects of instruction by practice assistants on inhaler technique and respiratory 
Citation: Bouros D, Evangeliou MN (2016) Critical Steps: A Non-Interventional, Multicenter, Prospective, Observational Study on Critical Handling Errors with DPI Use, in Asthma and COPD Patients. J Pulm Respir Med 6: 360. doi:10.4172/2161-105X.1000360

Page 8 of 8

symptoms of patients. A controlled randomized videotaped intervention study. Fam Pract 13: 35-40.

17. Perpiñá Tordera M, Viejo JL, Sanchis J, Badia X, Cobos N, et al. (2008) Assessment of patient satisfaction and preferences with inhalers in asthma with the FSI-10 Questionnaire. Arch Bronconeumol 44: 346-352.

18. Juniper EF, O’Byrne PM, Guyatt GH, Ferrie PJ, King DR (1999) Development and validation of a questionnaire to measure asthma control. Eur Respir J 14: 902-927.

19. Juniper EF, Bousquet J, Abetz L, Bateman ED (2006) Identifying 'well-controlled' and 'not well-controlled' asthma using the Asthma Control Questionnaire. Respir Med 100: 616-621.

20. Jones PW, Brusselle G, Dal Negro RW, Ferrer M, Kardos P, et al. (2011) Properties of the COPD assessment test in a cross-sectional European study. Eur Respir J 38: 29-35

21. Kon SS, Canavan JL, Jones SE, Nolan CM, Clark AL, et al. (2014) Minimum clinically important difference for the COPD Assessment Test: a prospective analysis. Lancet Respir Med 2: 195-203.

22. Miravitlles M, García-Sidro P, Fernández-Nistal A, Buendía MJ, Espinosa de los Monteros MJ, et al. (2013) Course of COPD assessment test (CAT) and clinical COPD questionnaire (CCQ) scores during recovery from exacerbations of chronic obstructive pulmonary disease. Health Qual Life Outcomes 11: 147.

23. Tsiligianni IG, van der Molen T, Moraitaki D, Lopez I, Kocks JW, et al. (2012) Assessing health status in COPD. A head-to-head comparison between the COPD assessment test (CAT) and the clinical COPD questionnaire (CCQ). BMC Pulm Med 12: 20

24. Miller MR, Hankinson J, Brusasco V, Burgos F, Casaburi R, et al. (2005) Standardisation of spirometry. Eur Respir J 26: 319-338.
25. Grekas N, Athanassiou A, Iskos C, Panagiotakos D, Papataxiarchou A, et al. (2011) Reliability of the FSI-10 questionnaire for the assessment of the usability of drug inhalers in Greek patients. Arch Hellen Med 28: 257-260.

26. Grekas N, Athanassiou K, Papataxiarchou K (2013) Assessment of satisfaction with inhalation devices in Greek patients. Eur Respir J 42: 2403.

27. Global Initiative for Asthma (2014) Global Strategy for Asthma Management and Prevention.

28. Chrystyn $\mathrm{H}$ (2007) The Diskus ${ }^{\mathrm{TM}}$ : a review of its position among dry powder inhaler devices. Int J Clin Pract 61: 1022-1036.

29. Zervas E, Gaga M, Athanassiou K, Papataxiarchou K, Grekas N (2012) Assessing asthmatic patients' satisfaction with inhalation devices. Eur Respir J 40: Suppl.56.

30. Zervas E, Gaga M, Grekas N, Papataxiarchou K, Athanassiou K (2012) Assessment of satisfaction with inhalation devices in COPD patients. Eur Respir J 40: 758

31. Donohue JF (2005) Minimal clinically important differences in COPD lung function. COPD 2: 111-124.

32. Cazzola M, MacNee W, Martinez FJ, Rabe KF, Franciosi LG, et al. (2008) Outcomes for COPD pharmacological trials: from lung function to biomarkers. Eur Respir J 31: 416-469.

33. Santanello NC, Zhang J, Seidenberg B, Reiss TF, Barber BL (1999) What are minimal important changes for asthma measures in a clinical trial? Eur Respir J 14: 23-27.

34. Reddel HK, Taylor DR, Bateman ED, Boulet LP, Boushey HA, et al. (2009) An official American Thoracic Society/European Respiratory Society statement: asthma control and exacerbations: standardizing endpoints for clinical asthma trials and clinical practice. Am J Respir Crit Care Med 180: 59-99. 